The loss in weight of the meat was less than by cooking under similar conditions, and the meat was found to be rich in juices, of pleasant taste and smell, reminding one of roasted meat. These Rohrbeck steam sterilisers have now been erected, and are in use in a number of public slaughter-houses, as for example, Berlin, Dresden, Lubeck, Eisenach, Halle, Potsdam, \&c., and are recommended by the several Governments. The apparatus is mainly used for rerdering harmless the flesh of tuberculous animals where the bones, muscle, and lymph glands of the muscular tissue remain free from tuberculous changes, or (in the case where the lymph glands are affected) when the tuberculous process is not of recent date.

Whether the flesh of animals affected with septicæmia or pyæmia has its harmful properties removed by heat, such as is produced in the steam steriliser, still requires investigation.

Experiments tend to show that toxalbumins are not destroyed by temperatures of $100-120^{\circ} \mathrm{C}$ : That they are not destroyed by the ordinary processes of boiling and roasting has been long known and proved by numerous meat poisoning cases that have occurred among groups of persons.

Rietschel and Henneberg, of Berlin and Dresden, have also constructed a very useful form of steam steriliser. It is cheaper than that of Rohrbeck, and is in use at Leipzig, Stettin, Spandau, and elsewhere.

(c) The apparatus for extracting the fat from the flesh of animals affected with tuberculosis, cysticerci and trichinæ in a high degree, does not require much explanation. The fat, cut up into small pieces, is melted in ordinary boilers in which a temperature of $150^{\circ} \mathrm{C}$ is reached.

(d) By means of pickling, provided the process is allowed a long enough time to act (four weeks), and the pieces are not too large, meat affected with cysticerci and trichinæ can be rendered free from danger. The method is especially applicable in the case of country districts, where it is difficult to arrange for the cooking or sterilising of large quantities of meat. But the process is being introduced more and more in slaughterhouses, as pigs' fiesh prepared in this way, is bought up more readily than when it has been cooked.

(c) Treatment of meat unfit for human food. The flesh of animals or their organs which must be totally excluded from consumption, is to be destroyed, or utilised for trade purposes. The latter object is secured by manure manufactories, bone crushing, establishments, and the like. If the removal of the condemned meat to these establishments cannot be carried out under police supervision, then the meat should first be saturated with some strong-smelling medium, such as petroleum or carbolic acid, or be treated with destructive agents as the mineral acids, so as to render it impossible for it to be sold for food.

\section{FORMALDEHYDE DISINFECTION.}

\author{
By Dr. S, Rideal.
}

AT the recent conference at Leeds, the discussion which followed Dr. Kenwood's paper on the "Dis. infection of Rooms by Formic Aldehyde Vapours," induced me to describe some experiments upon which I have recently been engaged with a view to ascertaining in what way formaldehyde can be most advantageously employed for room disin. fection.

As these experiments have not yet been published it may be of interest to the readers of Public HEALTH if I give somewhat more fully the conclusions which I have at present formed from this investigation.

In I 894, in conjunction with Dr. Slater, I satisfied myself that the vapours of formaldehyde could be used for this purpose, and published the details of these early trials in the Lancet (1894, p. 1004). I then found that vaporizing "Formalin" in the proportion of I oz. per I, 000 cubic feet in a shallow dish over an ordinary spirit lamp reduced the number of organisms in the air from 429 per Io litres to $7 \mathbf{I}$, and that the majority of cultures exposed to the vapour gave only feeble subcultures, whilst $B$. typhosus and $B$. coli were killed.

This quantity corresponds to $0^{\circ} 4 \mathrm{oz}$. formaldehyde per $1,25^{\circ}$ ozs. of air or ${ }^{\circ}, 3^{2}$ per cent. by weight. As formaldehyde has practically the same density as air this is also $\cdot 032$ per cent. by volume. Within the last year there have, however, been introduced three distinct methods of applying formaldehyde to room disinfection, all of which possess advantages over the method which they then adopted. They are :

(I) Spraying the walls, ceiling and floor with the solution.

(2) Atomising the vapour from a calcium chloride solution under pressure in an autoclave.

(3) Vaporizing paraformaldehyde by means of heat in the presence of water vapour produced from the products of combustion of methylated spirit.

I. The Sprayer (Equifex apparatus).-Dr. Kenwood in his paper suggests the use of 2.5 per cent. solutions of the aldehyde for spraying, but as he seems prejudiced against the use of a spray apparatus he has not used this process in practice. Drs. Leslie Mackenzie and Alexander, at Leith and Poplar, have, on the other hand, already reported in its favour, and use 2 ozs. of formalin per gallon or a $0^{\circ} 5$ per cent. solution of formaldehyde. This latter strength is the one which $I$ have advocated for some time, as it is certainly strong enough. for all general purposes, and far in excess of the strength required to inhibit the growth of most commonly occurring organisms, as the following table shows - 


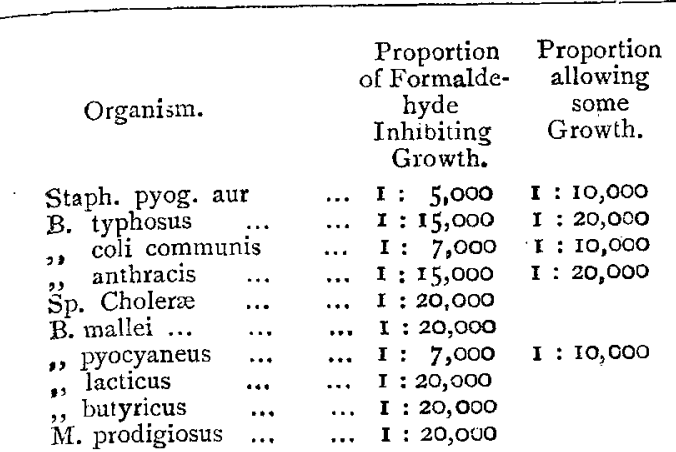

The 0.5 per cent. solution is therefore 35 to roo times stronger than is necessary to kill the above organisms, and I am therefore of the opinion that Dr. Kenwood's strength of $2 \cdot 5$ per cent. is much too high. Dr. Mackenzie states that there is no difficulty in respiration felt by the disinfector asing the $0^{\circ} 5$ per cent. strength whilst the higher strength suggested but not used by Dr. Kenwood would, I believe, be usually found somewhat irritating to work with. As I mentioned at Leeds, my own view is that I agree with $\mathrm{Dr}$. Kenwood in the risk of imperfect spraying except with a good sprayer like the Equifex in the hands of an experienced operator, and that therefore the spraying with a $0^{\circ} 5$ per cent, solution should in all cases be followed by the use of a paraform lamp so as to ensure the disinfection by vapour of crevices and parts of the room or furniture missed by the spray, I therefore rely more on the lamp than the spray, and would confine the combined use of the spray and lamp to those cases in which we are dealing with an unknown organism like small-pox, or when the walls and room are exceptionally dirty and very special disinfection seems indicated.

(2.) The Autoclave (Trillat's apparatus).-Dr. Kenwood has obtained perfect sterilization of diptheria swabs with this apparatus. Dr. Sims Woodhead stated at the Conference that at a trial of the autoclave on the Embankment, unsuccessful results were obtained. My own results were most satisfactory, but as they have already been published in full by the proprietors of the autoclave in this country, I need not refer to them in detail here. There are, however, certain points in Dr. Kenwood's paper which need comment.

(a) The time required: this he states correctly to be an hour, viz, half-an-hour for heating, and half-an-hour for discharge into the room; but later in his paper he concludes that Trillat's apparatus is to be preferred to the lamp, as it takes only half-an-hour.

(b) Quantity. This he states to be $I^{\prime} 5$ litres Formalin = say 600 grammes, or $20 \mathrm{oz}$, of Formaldehyde for 3,000 cubic feet capacity $=20$ oz. per $3,75 \circ \mathrm{O} z .={ }^{\circ} 5$ per cent., and not, as he states, 2 per cent. It is true that later he says "doubtless under I per cent. suffices," but as already mentioned in my earlier experiments with formalin solution vaporized, I used only 032 per cent, and in the lamps, to grammes of paraform per $\mathrm{I}, 000$ cubic feet $=33 \mathrm{oz}$. per $\mathrm{r}, 250 \mathrm{oz} .=025$ per cent. have given satisfactory results both at his hands and in my own experiments. The quantity used in the autoclave is therefore about twenty times that required by the lamp, and consequently increases the cost of each disinfection apart from the initial cost of the apparatus.

My own conclusion with regard to the autoclave is that it does the same work as the smaller and cheaper lamps, but that it is far more difficult and more costly to work.

(3.) The Paraform Lants. (The Alformant.)--. Dr. Kenwood obtained sterilization of exposed diphtheria swabs with the paraform lamp, using to grammes per $\mathrm{I}, 000$ cubic feet, and with a lamp burning $x \frac{1}{2}$ litres of methyl alcohol per 2,000 cubic feet.

I have no experience of the methyl alcohol lamps, and have not paid any attention to them as I have thought that the conversion of methyl alcohol in situ into active formaldehyde must be far from complete and must vary with the conditions of the experiment. It is satisfactory, however, to find that Dr. Kenwood has found that sufficient formaldehyde is formed from $\mathrm{r}_{\frac{1}{2}}$ litres of alcohol to disinfect a room of 2,000 cubic feet under the conditions stated.

I have now had considerable experience with the paraform lamps, and these experiments have not been published. I give them here in detail.

I have used in all the experiments a room of I, 500 cubic feet, and in the first experiments endeavoured to find the minimum quantity of of paraformaldehyde which would disinfect. I found that

(a) $\mathrm{r}$ gramme per $\mathrm{I}, 000$ cubic feet did not kill $B$. coli communis when the room was sealed for four hours.

(b) That 6 grammes per $\mathrm{x}, 500$ cubic feet $(=$ 4 grammes per 1,000 cubic feet) killed $B$. coli communis and Staph. pyog. aur. exposed on silk threads, but not when the cultures were soaked into paper slips, the room being sealed for six hours.

(c) With $\mathbf{2} 2$ tablets per $\mathbf{1}, 500$ cubic feet (8 grammes per 1,000$)$ B. coli communis and Staph. pyog. aur. were killed on paper slips.

(d) With I $_{5}$ tablets per 1,500 cubic feet (10 grammes per 1,000 cubic feet) I succeeded in killing $B$. coli communis, $B$. typhosus, $B$. diphtheriae, Staph. pyog. ausr. when the room was sealed for 20 hours and the organisms exposed on silk threads, paper slips, and inside rolls of linen which had been dipped into the cultures. $B$. anthracis and $B$. subtilis exposed in the same three ways were not killed in this experiment.

(e) Using 20 tablets per $\mathrm{I}, 500$ feet $=$ ( $\mathrm{I} 3.3$ grammes per $\mathrm{t}, 000$ cubic feet) and exposing $B$. anthracis and $B$. subtilis both containing spores, I failed to 
sterilize the silk threads or paper slips when they were exposed in the centre of the room on the same level as the lamp, but the $B$. anthracis exposed on a linen slip near the wall was found to be sterile.

(f) On repeating this experiment, using 20 grammes per $I, 000$ cubic feet as before, $I$ found that silk threads infected with $B$. anthracis, and exposed (I) six feet over the lamp and (2) near the wall, were sterilized. A dry paper slip similarly infected near the wall, gave growths on subculture, but those from a wet slip were much attenuated and did not appear until the fourth day. A fold of dry linen infected with an anthrax culture similarly placed was not sterilized, but the organisms in another fold wetted and then infected were killed.

(g) Further experiments in August lasi were started to determine whether it was necessary to remove infected linen, etc., from the room when formaldehyde was employed in this way, in other words, to ascertain its penetrating power.

I found that with ro grammes per I,000 cubic feet, pieces of damp linen infected with Staph. pyog. aureas culture and placed in test tubes plugged with cotton wool, were not sterilized when they had been exposed within eight folds of a heavy blanket and when buried in the centre of a feather pillow; on the other hand, when 20 grammes per $I, 5$ co cubic feet were tried, infected linen sealed in a sterile paper envelope exposed on a table in the room was sterile, and the infected linen from similar envelopes placed inside the pillow and between eight folds of the blanket dia not give any growth of the staphylococcus after subculture, although in the last two cases the broth of the subculture became turbid from some other adventitious organism.

It will be seen from the above experiments that I have obtained sufficient good results with Io grammes per $x, 000$ cubic feet to warrant this quantity being used in all cases of ordinary disinfection, and if in special cases the walls and floors are in addition "sprayed with a 0.5 per cent. Formalin solution before using the lamp, I believe that the best practical means of disinfection would be in this way ensured.

SlaUghrer-HoUses in BATH.-At a meeting of the Bath Sanitary Committee, held on October 4 th, the sub-committee recommended that if a person or a private company would submit plans for the erection of slaughter-houses on an improved site they should be favourably entertained. This recommendation was adopted, and a resolution was passed urging the Corporate Property Committee, who own the slaughter-houses in Parson's Yard, to treat for the surrender of the lease in order to close them. $-B . M . J$.

\section{CURRENT PUBLIC HEALTH LITERATURE.}

Mortality from Certain Causes in London, Paris, Berlin, and Vienna, and in Several of the States of Europe, by Dr. NaHts, of the Imp. Statist. Office.

$$
\text { (Arb. a. a. K. Ges. Ba. xiv. k. 3.) }
$$

THE populations of London and Berlin (the former on the whole better housed, the latter with the better sewerage and water supply) are almost identical in every respect save infant mortality, which is higher in Berlin, perhaps through overcrowding. The enormous difference in age constitution between the populations of these cities and of Paris shows the necessity of appropriate correction before comparing the recorded deathrates. Illegitimacy and still-births (?) are fearfully prevalent in Paris, suggesting the association of the two. While children form 25 per mille of the population of London and of Berlin, and $2 \mathrm{I}$ per mil. of that of Vienna, they constitute only 12.4 per mil. of the population of Paris. To $I, 000$ live births there are in France 179 illegitimate, in Prussia 77, and in Italy 72 . [These figures apply to the entire nations, and cannot, therefore, be explained away by the social conditions of Paris itself.-Rep.] The still births to each $I, 000$ live births are $3 \mathrm{I}$ in Berlin and $7 \mathrm{I}$ in Paris. In England these are not registered. For 10,000 births the mothers dying in childbed were 40 in Berlin, 43 (?) in London, and 53 in Paris. The London figures are probably misleading, from the fact that there would be no registered birth in the case of death following premature delivery, or when the death of the mother was associated with a still birth at full term. In infant mortality alone does Paris show to advantage, viz., $x_{3} 8$ as against 240 in Berlin per 1,000 born alive. [But as 138 per $I, \infty 00$ is lower than that of France as a whole, and indeed of any great town or country in Europe with the single exception of Norway, it cannot represent the truth, but must be explained by the practice of sending infants out to nurse in the provinces.-REP.] The probability at birth of reaching the age of 20 years, and at 20 of reaching that of 60 years, is greater in London and Berlin than in Vienna or Paris, the mean annual deathrate per 10,000 living in the former period being in Berlin 107, London x10, Paris 139 , and Vienna $x 60$, and in the second, Berlin, xo4; London, I28; Vienna, I 36 ; and Paris, 142 . The annual mortality per 10,000 of the population from tuberculosis and respiratory diseases is in Berlin, 45 ; London, 54; Vienna, 69; and Paris, 70; and from scarlatina, Berlin and London, 28 ; Paris, 34 ; Vienna, 44. [If these rates for scarlatina were calculated on the age period to which the disease is almost restricted, viz., O-I 5 years, Paris would come out worst, for the child element 